\title{
Synthesis of Oxopyrazolidine-1-carboximidamides from Morita Baylis-Hillman adducts
}

\author{
Manoel T. Rodrigues Jr., José Tiago M. Correia and Fernando Coelho*
}

Laboratório de Síntese de Produtos Naturais e Fármacos, Instituto de Química, Universidade Estadual de Campinas-UNICAMP, Caixa Postal 6154, 13083-970, Campinas-SP-Brazi

*coelho@iqm.unicamp.br:

Keywords: Pyrazolidin-3-ones ,Oxopyrazolidine-1-carboximidamides, Morita-Baylis-Hillman (MBH) Reaction

\section{INTRODUCTION}

Pyrazolidin-3-ones derivatives, including 5oxopyrazolidine-1-carboximidamides, are an important class of compounds, which possess widespread pharmacological properties such as analgesic, antipyretic and anticancer. Several synthetic approaches have been developed to access pyrazolidin-3-one rings. In this work we disclose a facile and diastereoselective synthetic approach to prepare oxopyrazolidine-1carboximidamides derivatives from Morita-BaylisHillman (MBH) adducts. Our approach is based on a tandem sequence involving a Michael addition reaction and cyclization, which forms in a single step a new cycle and controls the relative stereochemistry of two centers.

\section{RESULTS AND DISCUSSION}

The $\mathrm{MBH}$ adducts were prepared according to a methodology we described some years ago. In brief, aldehydes were treated with methyl acrylate to provide the corresponding $\mathrm{MBH}$ adducts (7-11) in good yield. Treatment of $\mathrm{MBH}$ adducts 7-11 with TBS trifluoromethanesulfonate gave the corresponding silylated derivatives (12-16) in excellent yields (Table 1).

Table 1. Preparation of silylated $\mathrm{MBH}$ adducts

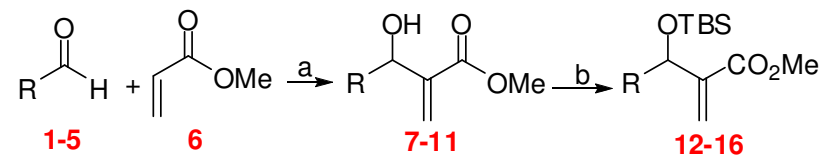

Reagents and conditions: $a$. DABCO, ultrasound; $b$. TBSOTf, $\mathrm{Et}_{3} \mathrm{~N}, \mathrm{CH}_{2} \mathrm{Cl}_{2}$, r.t.

\begin{tabular}{|c|c|c|c|}
\hline Entry & $\mathbf{R}$ & Adduct (a) & Silylation (b) \\
\hline $\mathbf{1}$ & $3-\mathrm{Cl}-\mathrm{Ph}$ & $7,91 \%$ & $12,>99 \%$ \\
3 & $2-\mathrm{F}-\mathrm{Ph}$ & $8,87 \%$ & $13,94 \%$ \\
4 & $4-\mathrm{OMe}-\mathrm{Ph}$ & $9,72 \%$ & $14,>99 \%$ \\
5 & $\mathrm{Py}$ & $10,81 \%$ & $15,93 \%$ \\
& $4-\mathrm{NO}_{2}-\mathrm{Ph}$ & $11,97 \%$ & $16,97: \%$ \\
\hline
\end{tabular}

Having the $\mathrm{MBH}$ adducts in our hands, we react them with aminoguanidine carbonate (1.5 eq.) in the presence of triethylamine. Some oxopyrazolidine-1carboximidamides were easily prepared in good yield and high diastereoselectivity (Table 2). We rationalize that the diastereoselectivity is resulting from the control exerted by the voluminous silyl group. Our previous results support this proposition.

Table 2. Oxopyrazolidine-1-carboximidamides from $\mathrm{MBH}$ adducts.

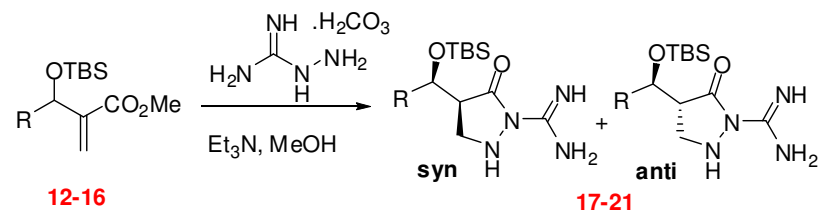

\begin{tabular}{|c|c|c|c|}
\hline Silylated adduct & $\mathbf{R}$ & Yield & Prod./Diast \\
\hline 12 & $3-\mathrm{Cl}-\mathrm{Ph}$ & 79 & $17,5: 1$ \\
13 & $2-\mathrm{F}-\mathrm{Ph}$ & 77 & $18,6: 1$ \\
14 & $4-\mathrm{OMe}-\mathrm{Ph}$ & 81 & $19,5: 1$ \\
15 & $\mathrm{Py}$ & 57 & $20,5: 1$ \\
16 & $4-\mathrm{NO}_{2}-\mathrm{Ph}$ & 80 & $21,3: 1$ \\
\hline
\end{tabular}
the coupling constant of the carbinolic proton.

\section{CONCLUSION}

In summary, we have demonstrated that oxopyrazolidine-1-carboximidamides can be prepared in good yields and diastereoselectivity from $\mathrm{MBH}$ adducts.

\section{ACKNOWLEDGEMENTS}

We thank FAPESP and CAPES for financial support.

\section{REFERENCES}

${ }^{1}$ Gadad, A. K.; Mahajanshetti, C. S.; Nimbalkar, S.; Raichurkar, A. Eur. J. Med. Chem. 2000, 35, 853.

${ }^{2}$ Coelho, F.; Almeida, W. P.; Mateus, C. R.; Feltrin, M.; Costa, A. M. Tetrahedron 2001, 57, 6901.

3. Rodrigues Jr., M. T.; Gomes, J. C.; Smith, J.; Coelho, F. Tetrahedron Lett. 2010, 51, 4988. 